\title{
A DNA Repair Inhibitor Isolated from an Ecuadorian Fungal Endophyte Exhibits Synthetic Lethality in PTEN-Deficient Glioblastoma
}

Nneoma Adaku, ${ }^{\dagger^{\star}}$ Hyun Bong Park,${ }^{\ddagger} \S^{\star}$ Daniel J. Spakowicz, ${ }^{\wedge}$ Meetu Kaushik Tiwari, ${ }^{\dagger}$ Scott A. Strobel, ${ }^{\S \wedge}$ Jason M. Crawford, ${ }^{\ddagger, \S, \mid, 0}$ and Faye A. Rogers ${ }^{\dagger, \nabla, 0}$

\section{Author Affiliations: \\ ${ }^{\dagger}$ Department of Therapeutic Radiology, Yale School of Medicine, New Haven, CT 06520 †Department of Chemistry, Yale University, New Haven, CT 06520 \\ ${ }^{\S}$ Chemical Biology Institute, Yale University, West Haven, CT 06516 \\ ^Department of Molecular Biophysics and Biochemistry, Yale University, New Haven, CT 06520 'Department of Microbial Pathogenesis, Yale School of Medicine, New Haven, CT 06536 \\ ${ }^{\nabla}$ Yale Cancer Center, Yale School of Medicine, New Haven, CT 06520 \\ ${ }^{0}$ Correspondence should be addressed to: J.M.C. (email: jason.crawford@yale.edu) or F.A.R. (faye.rogers@yale.edu)}

${ }^{*}$ These authors contributed equally to this work. 


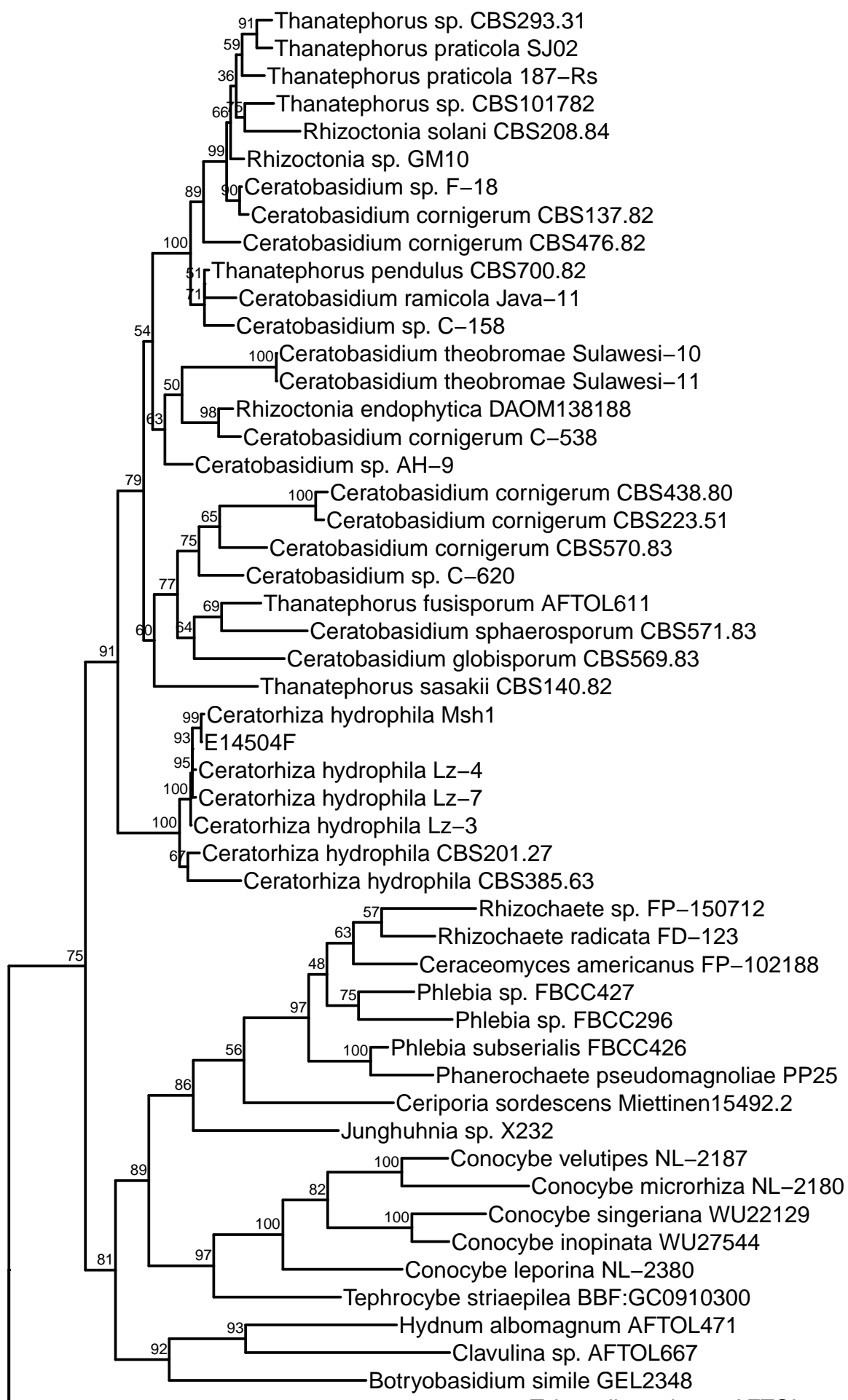




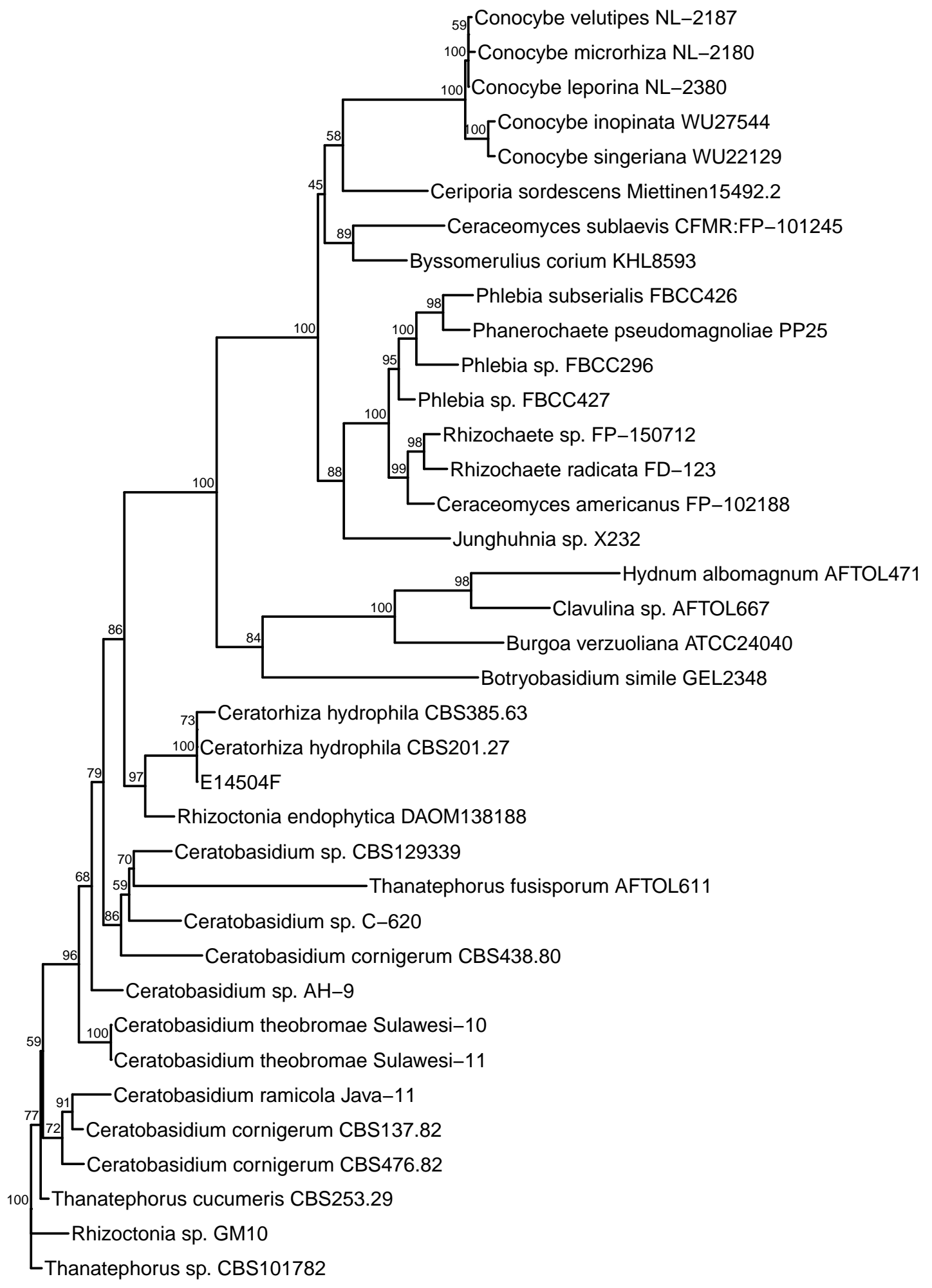

Fig. S2. E14505F single locus tree: LSU 


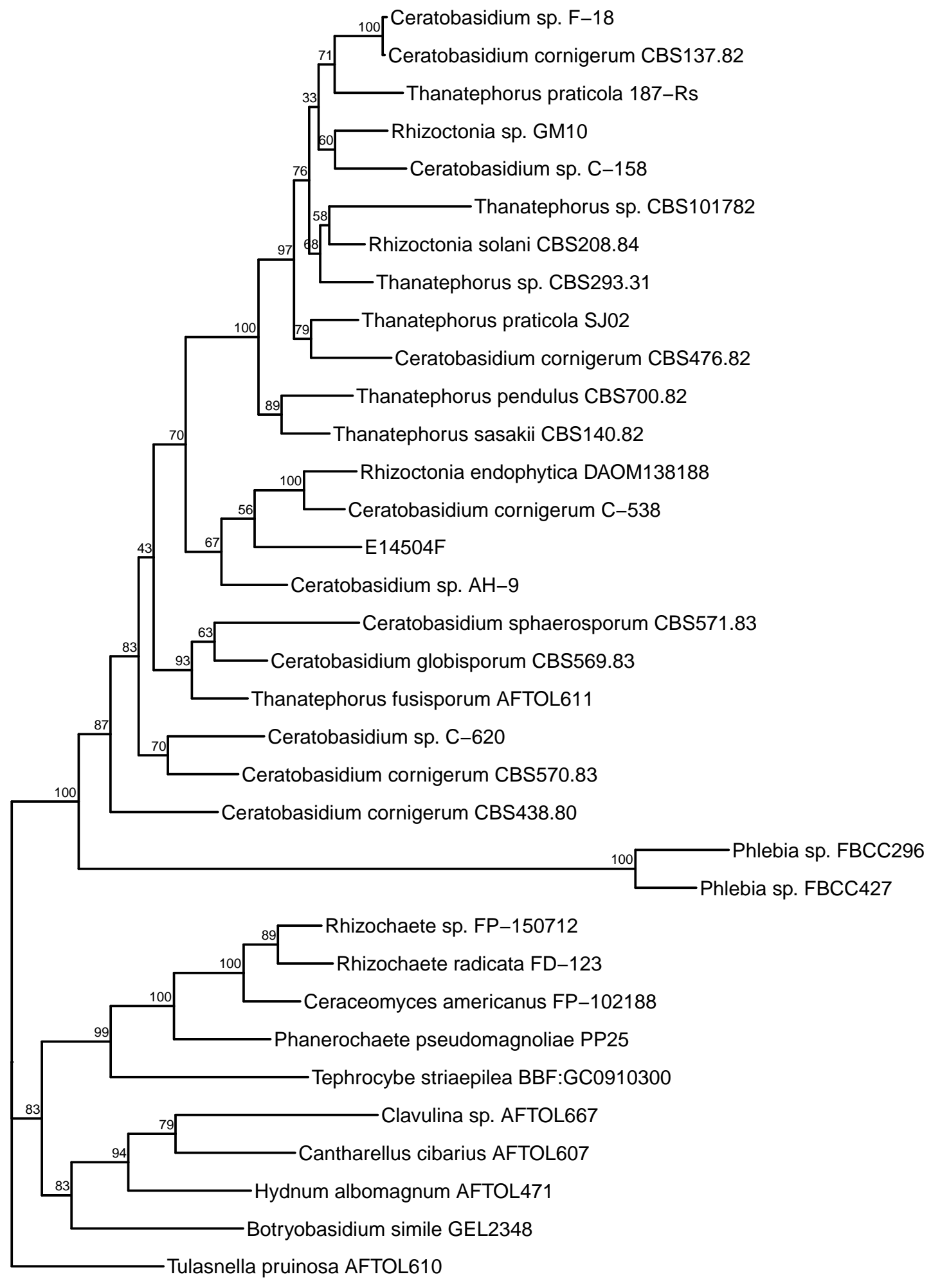

Fig. S3. E14505F single locus tree: RPB2 


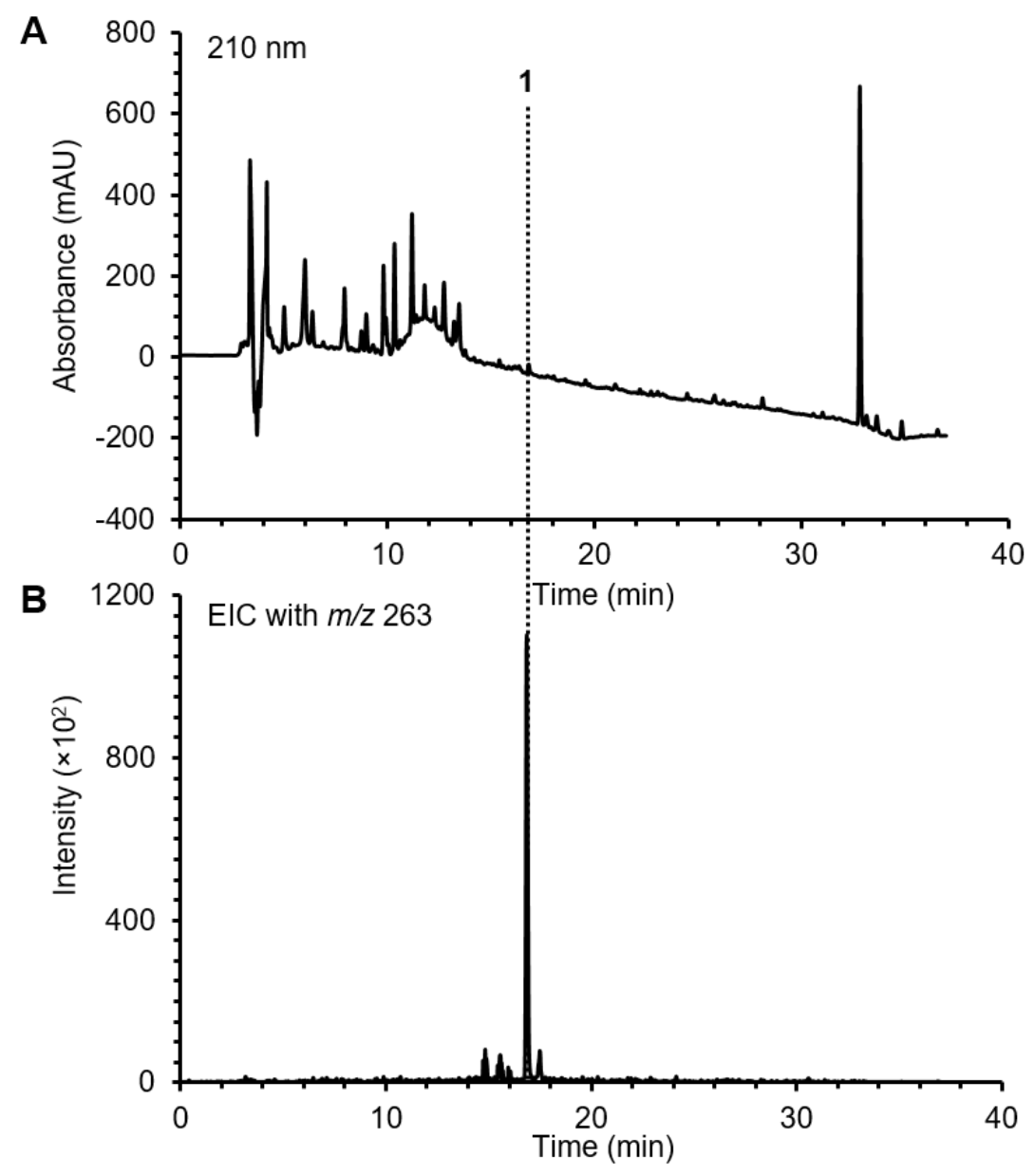

Figure S4. HPLC/MS analysis of methylene chloride-soluble materials from 6 I fungal culture broth. A, UV-visible chromatogram of organic materials monitored at a wavelength of $210 \mathrm{~nm}$. B, Extracted ion chromatogram with $\mathrm{m} / \mathrm{z} 263$ corresponding to protonated molecular ion of compound 1 in the positive ion mode. The reversed-phase $\mathrm{C}_{18}$ analytical chromatograms were collected using a gradient from 10 to $100 \%$ aqueous acetonitrile containing $0.1 \%$ formic acid over $30 \mathrm{~min}$ with a $0.7 \mathrm{ml} / \mathrm{min}$ flow rate (see Methods). 


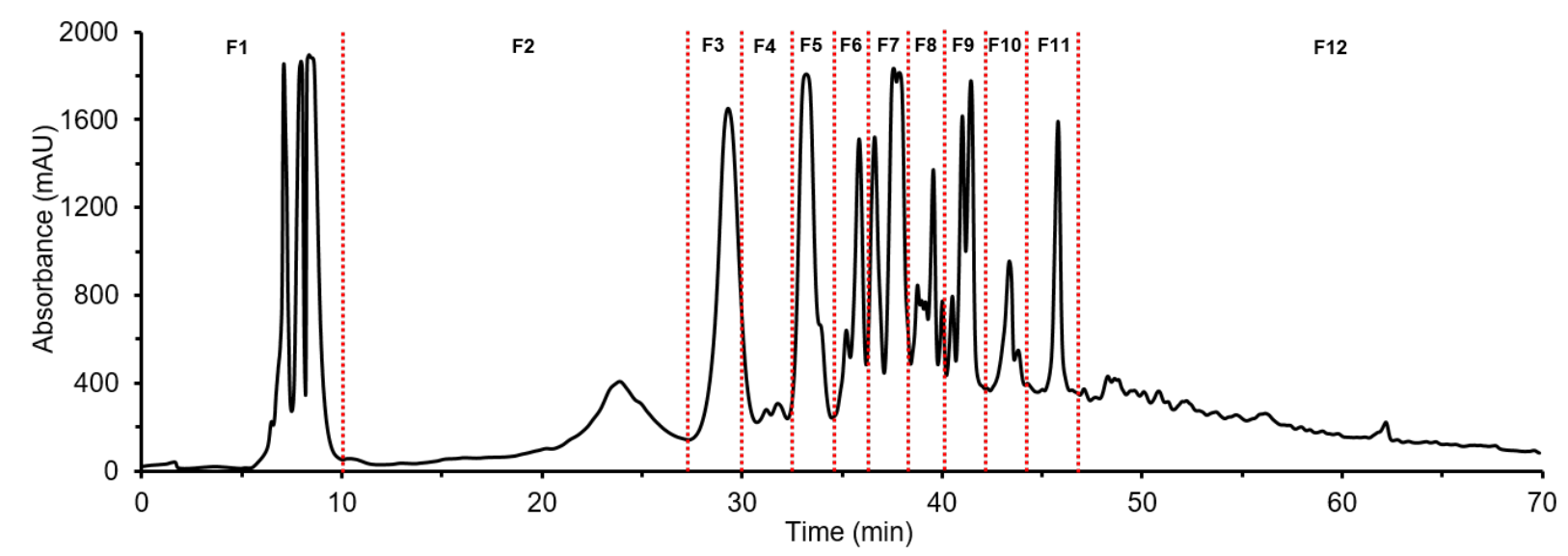

Bioassay-Guided Fractionation

\begin{tabular}{|c|c|c|c|}
\hline \multirow{2}{*}{ Fraction } & \multicolumn{2}{|c|}{ Percent Survival } & Difference in \\
& PTEN WT & PTEN -/- & Survival (\%) \\
\hline 04F-1 & 110.1 & 98.7 & 12.28 \\
\hline 04F-2 & 102.4 & 111.19 & -8.79 \\
\hline $04 \mathrm{~F}-3$ & 107.7 & 111.67 & -3.97 \\
\hline $04 \mathrm{~F}-4$ & 95.7 & 106.3 & -10.6 \\
\hline $04 \mathrm{~F}-5$ & 105.87 & 96.7 & 9.17 \\
\hline 04F-6 & 103.8 & 103.1 & 0.7 \\
\hline 04F-7 & 102.78 & 109.97 & -7.19 \\
\hline 04F-8 & 86.92 & 108.93 & -22.01 \\
\hline $04 \mathrm{~F}-9$ & 80.58 & 79.04 & 1.54 \\
\hline 04F-10 & 97.07 & 72.98 & 24.09 \\
\hline 04F-11 & 13.1 & 1.12 & 11.98 \\
\hline 04F-12 & 99.34 & 99.44 & -0.1 \\
\hline
\end{tabular}

Figure S5. HPLC/UV chromatogram for activity-guided fractionation of methylene chloride-soluble materials from 6 I fungal culture broth. HPLC chromatogram was recorded at $210 \mathrm{~nm}$. 


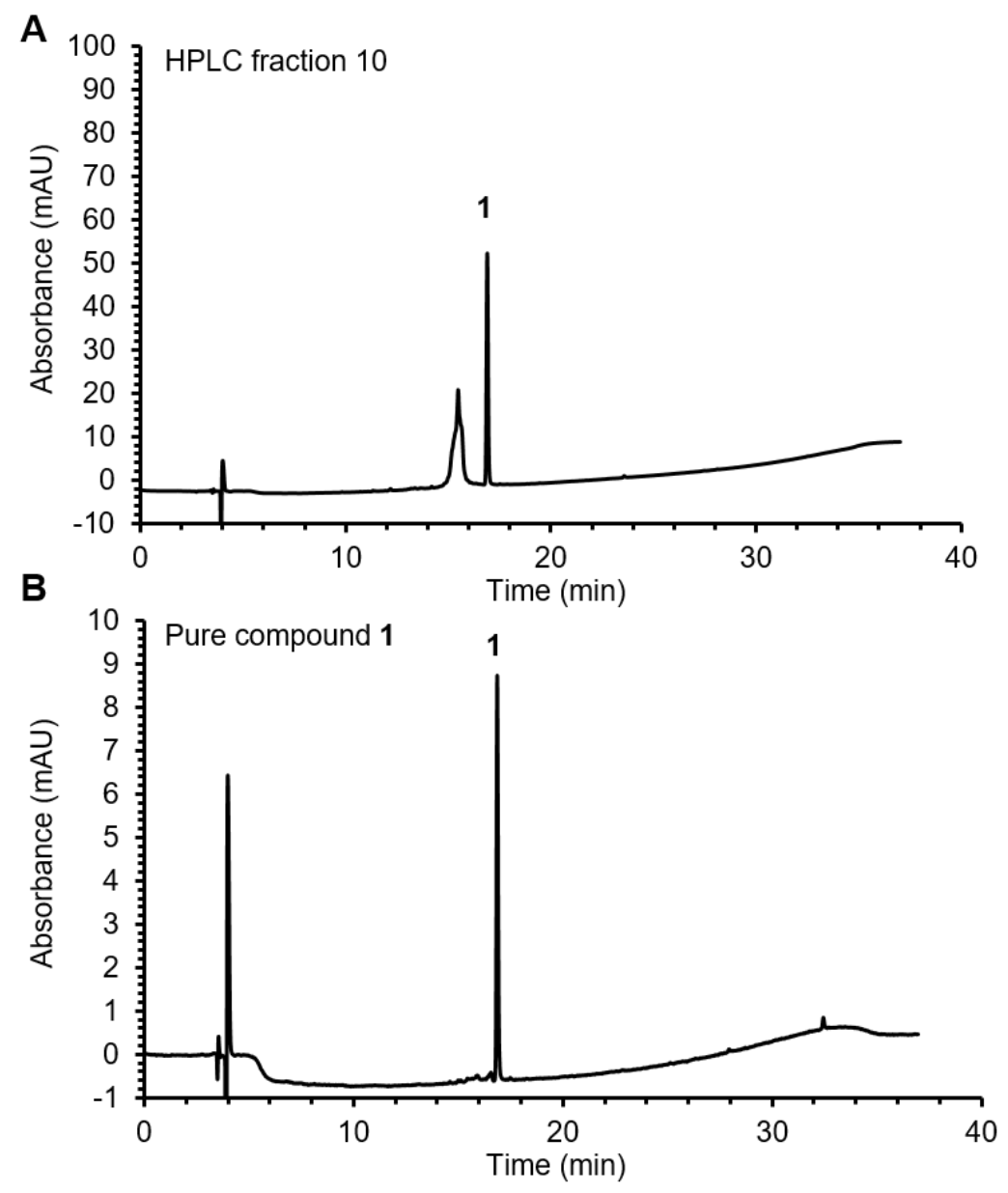

Figure S6. HPLC/UV analysis of active HPLC fraction 10 (A) and pure compound 1 (B) monitored at $210 \mathrm{~nm}$. 


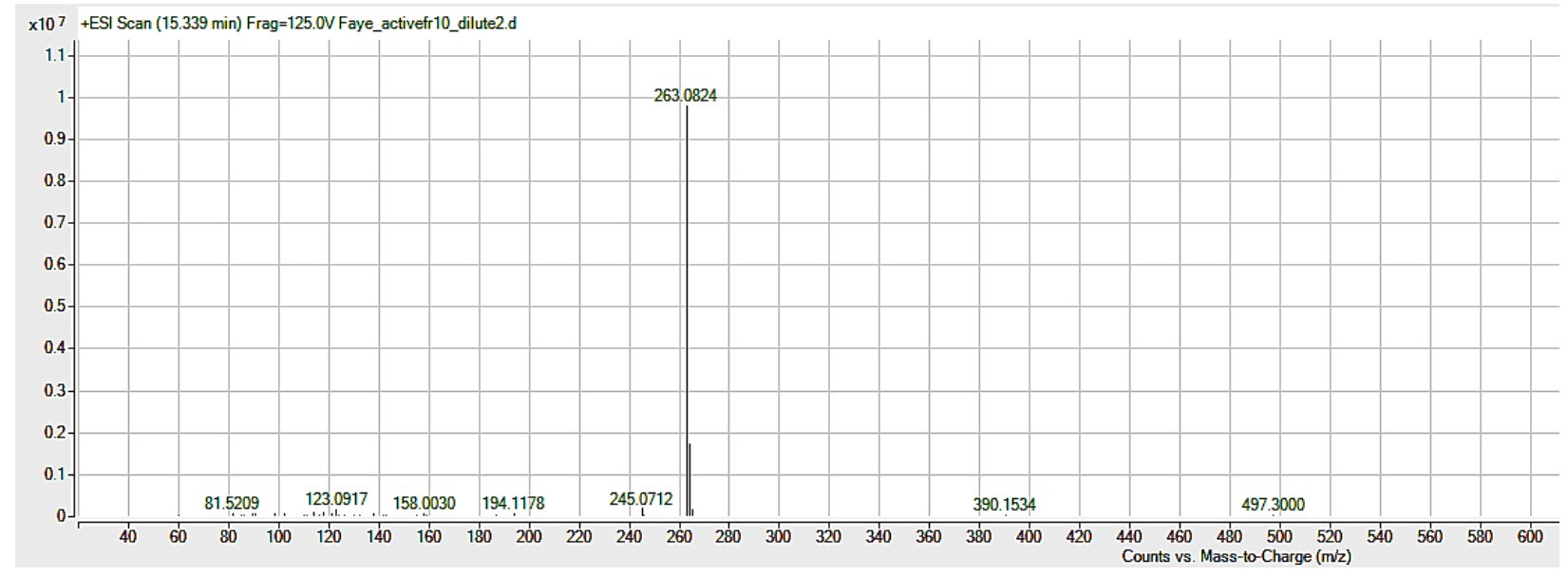

Figure S7. Observed HR-ESI-QTOFMS spectrum of compound 1.

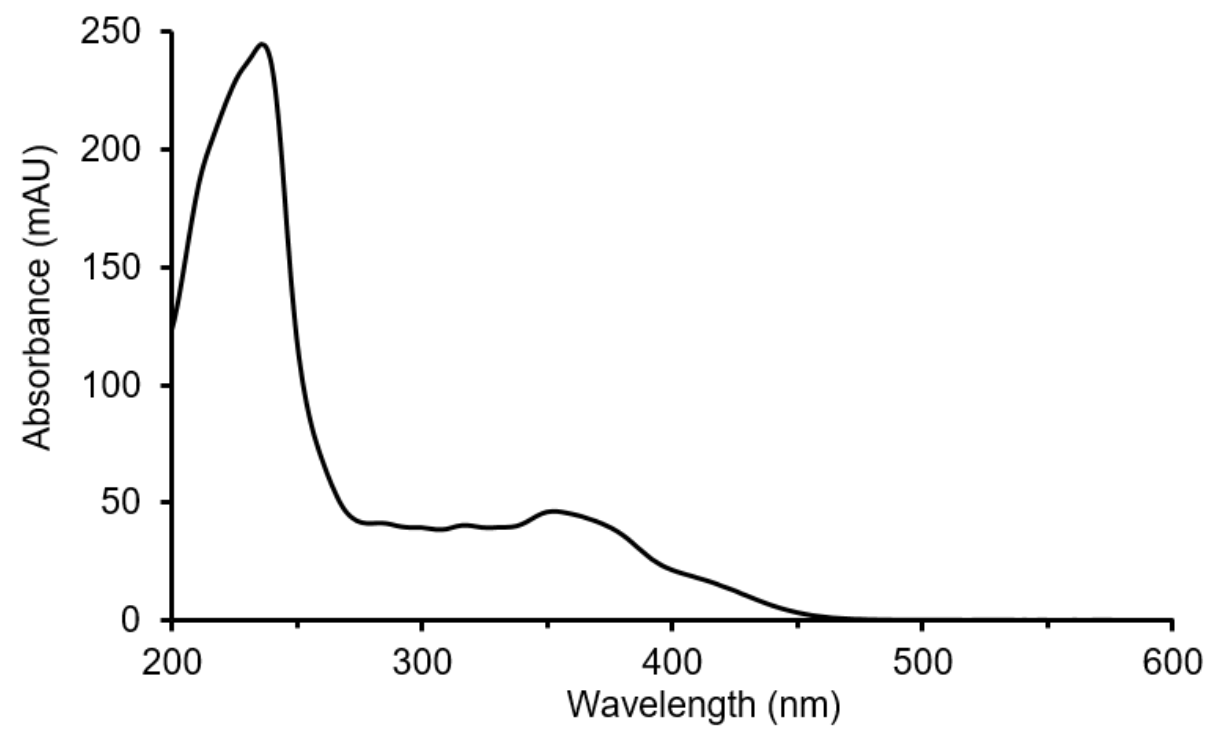

Figure S8. UV-visible spectrum of compound 1. 


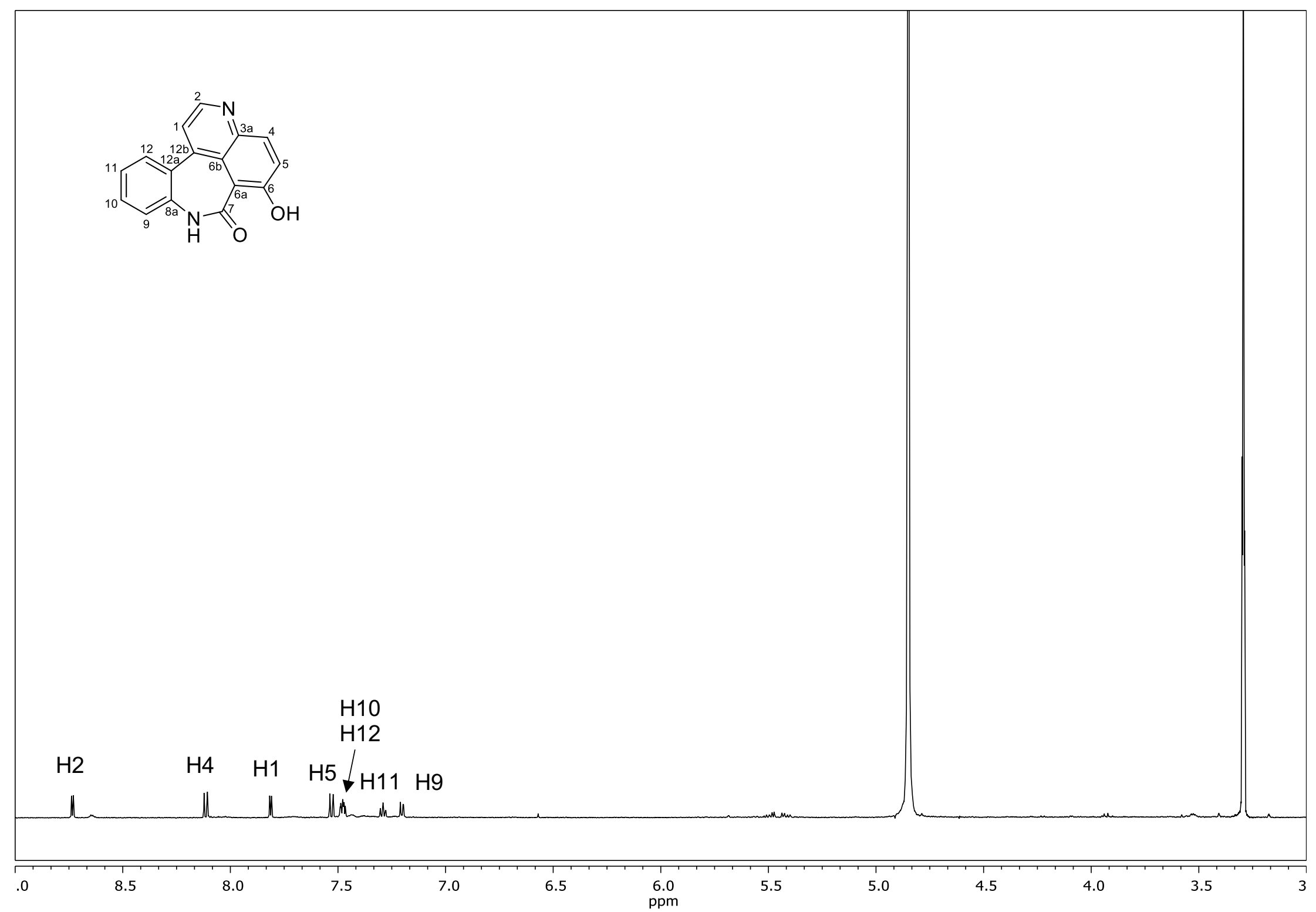

Figure S9. ${ }^{1} \mathrm{H}$ NMR spectrum of compound 1 in $\mathrm{MeOH}-d_{4}$ 


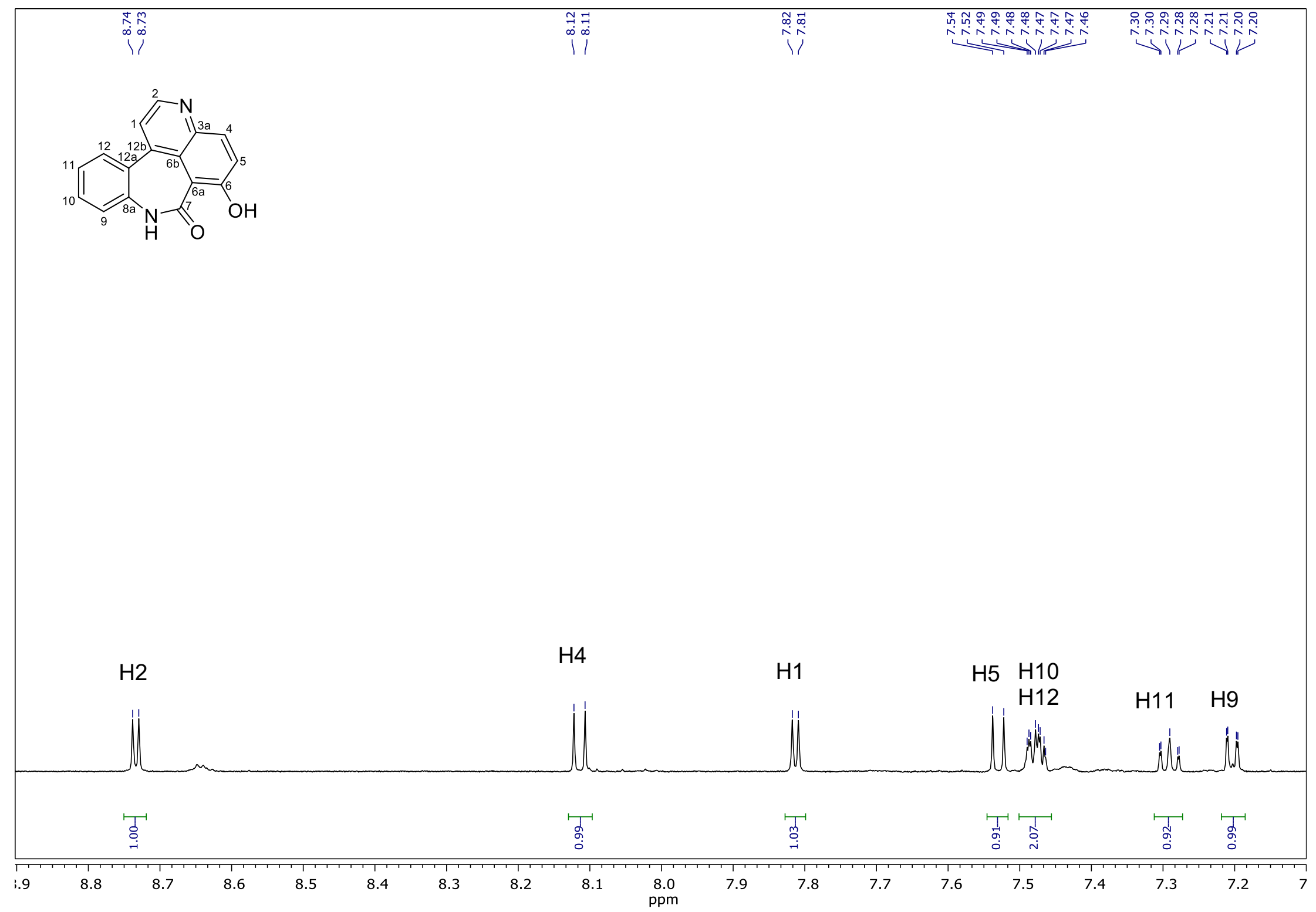

Figure S10. A blown-up spectrum of ${ }^{1} \mathrm{H}$ NMR of compound 1 in $\mathrm{MeOH}-d_{4}$ 


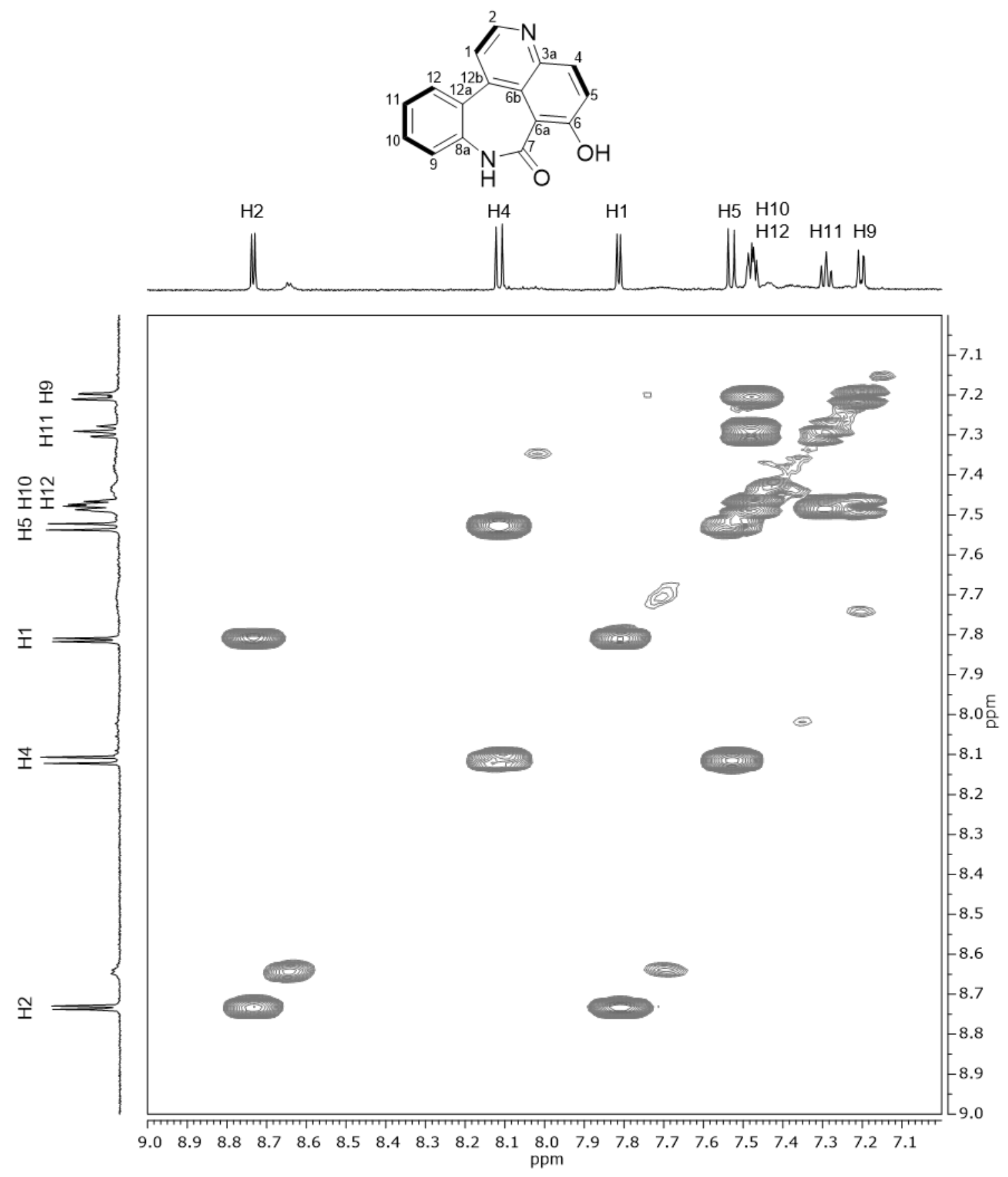

Figure S11. gCOSY NMR spectrum of compound 1 in $\mathrm{MeOH}-d_{4}$ 


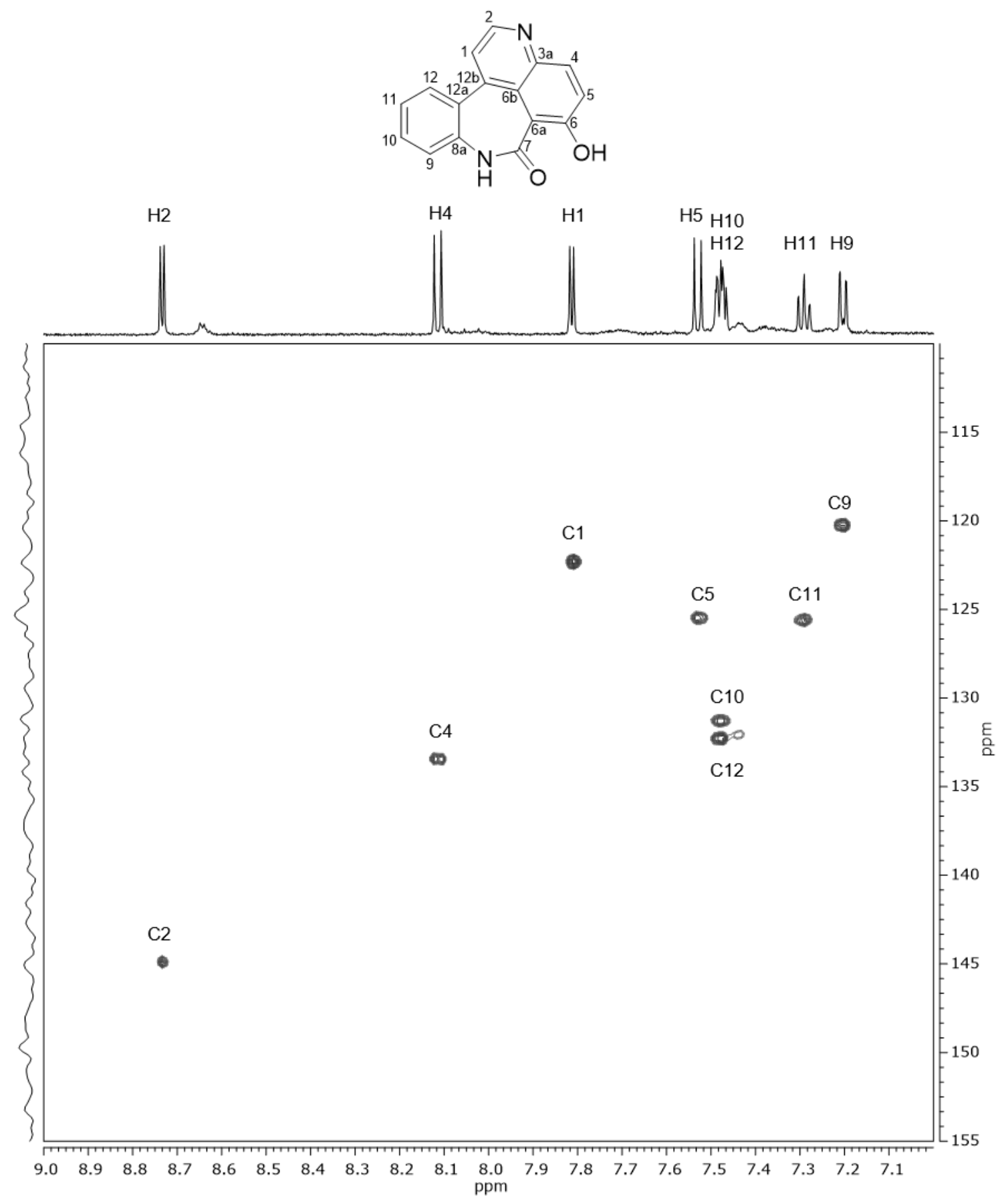

Figure S12. gHSQC NMR spectrum of compound 1 in $\mathrm{MeOH}-d_{4}$ 

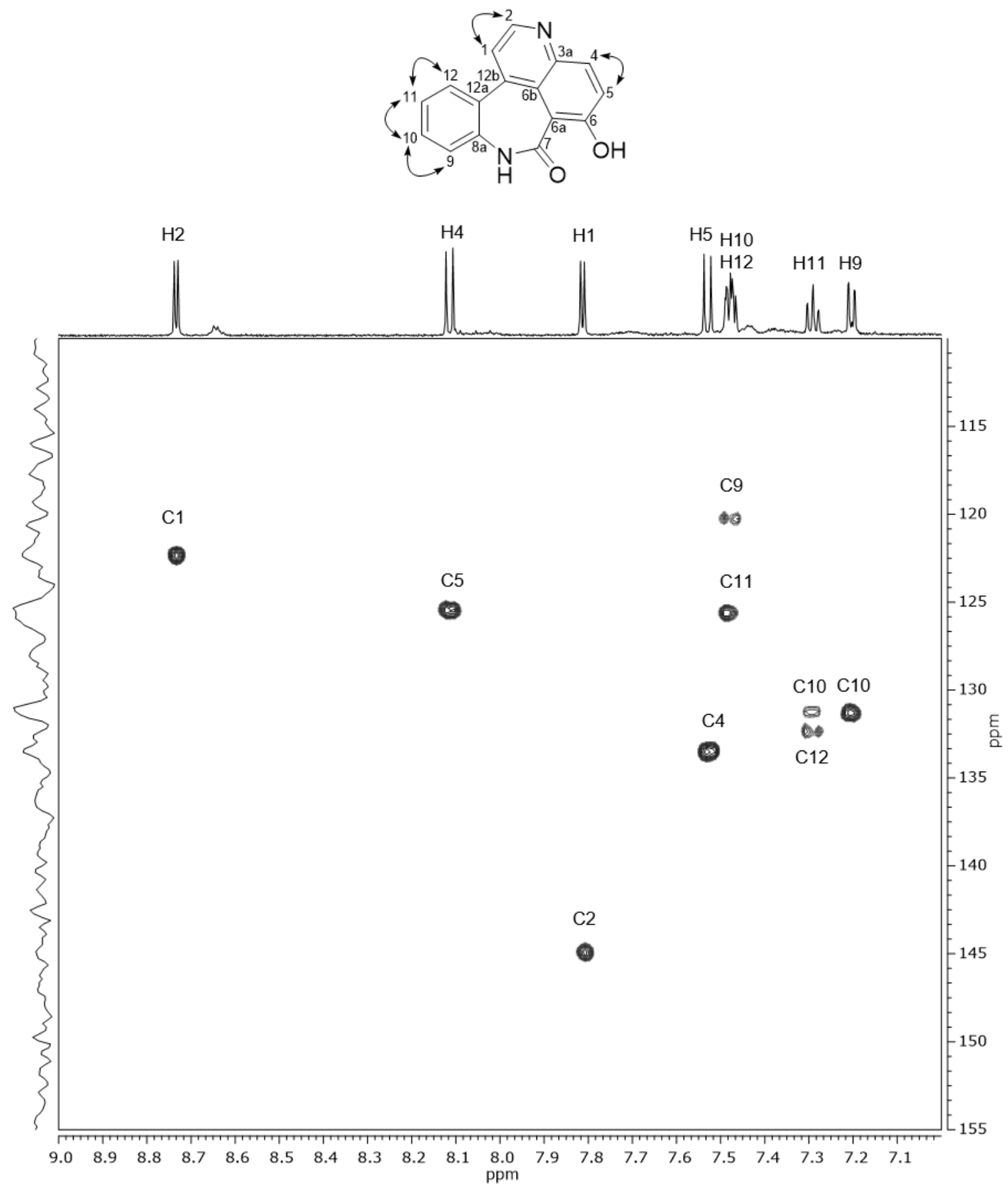

Figure S13. $\mathrm{gH} 2 \mathrm{BC}$ NMR spectrum of compound 1 in $\mathrm{MeOH}-d_{4}$ 

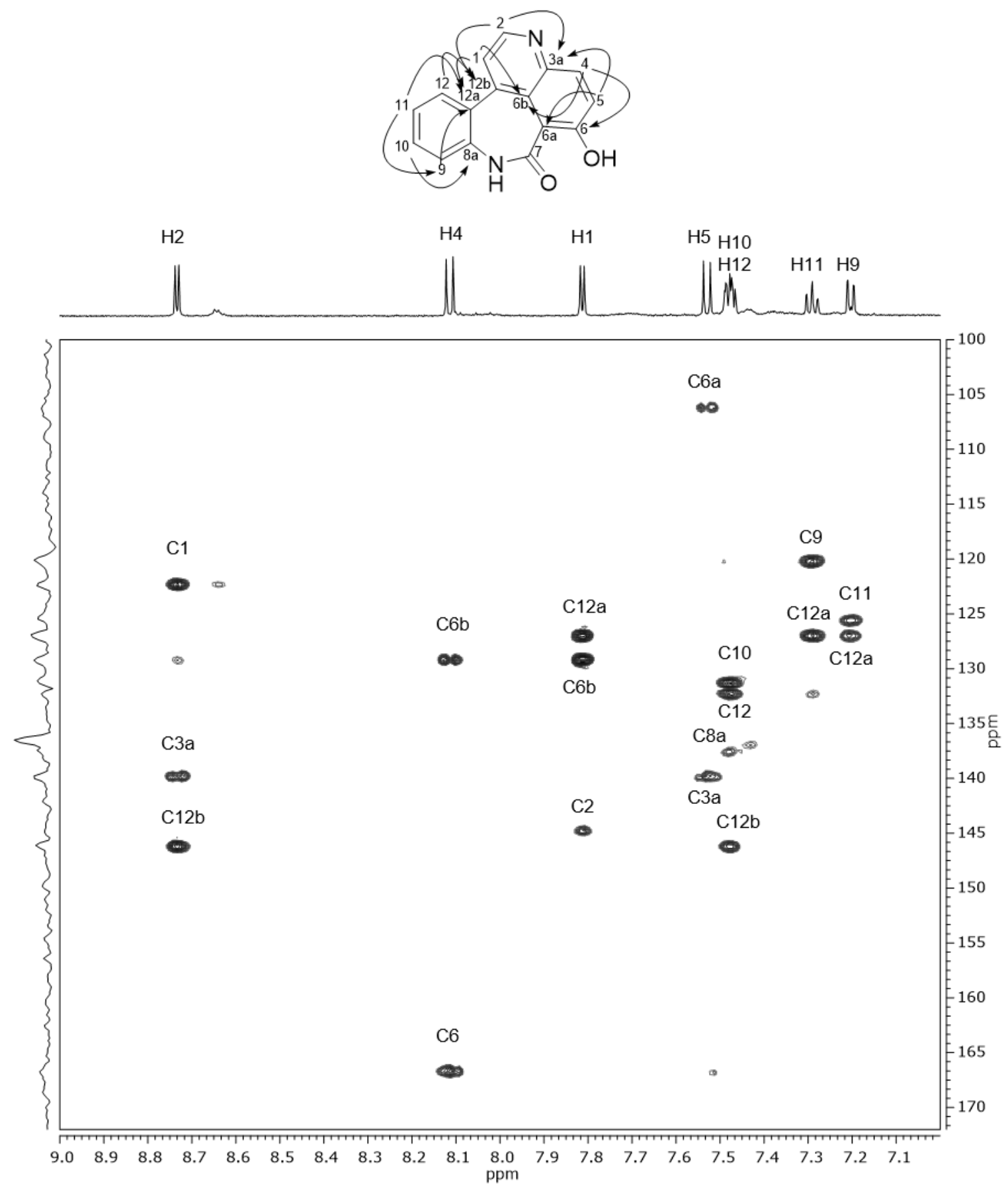

Figure S14. gHMBC NMR spectrum of compound 1 in $\mathrm{MeOH}-d_{4}$ 


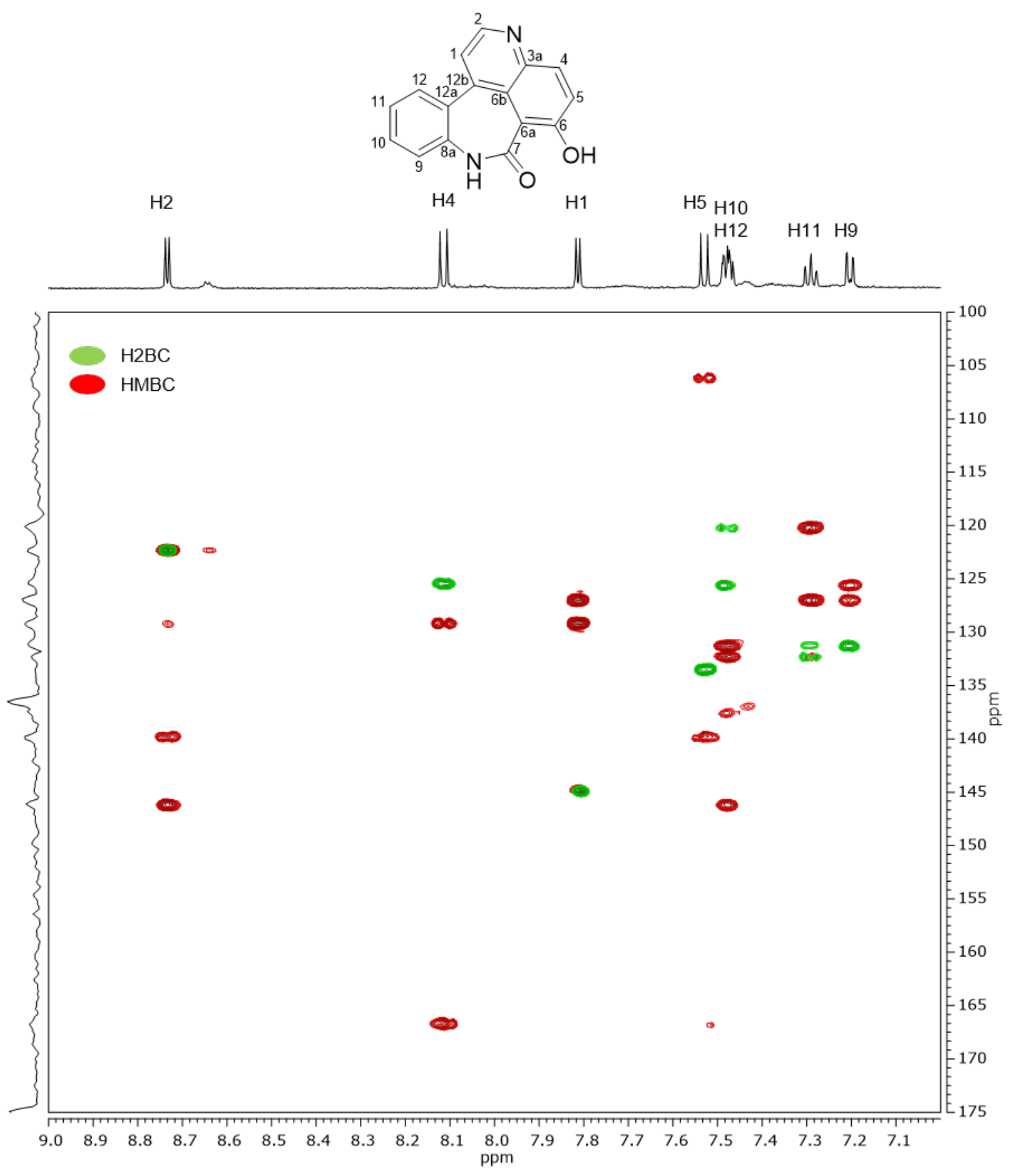

Figure S15. Merged gH2BC and gHMBC NMR spectrum of compound 1 in $\mathrm{MeOH}-d_{4}$ 


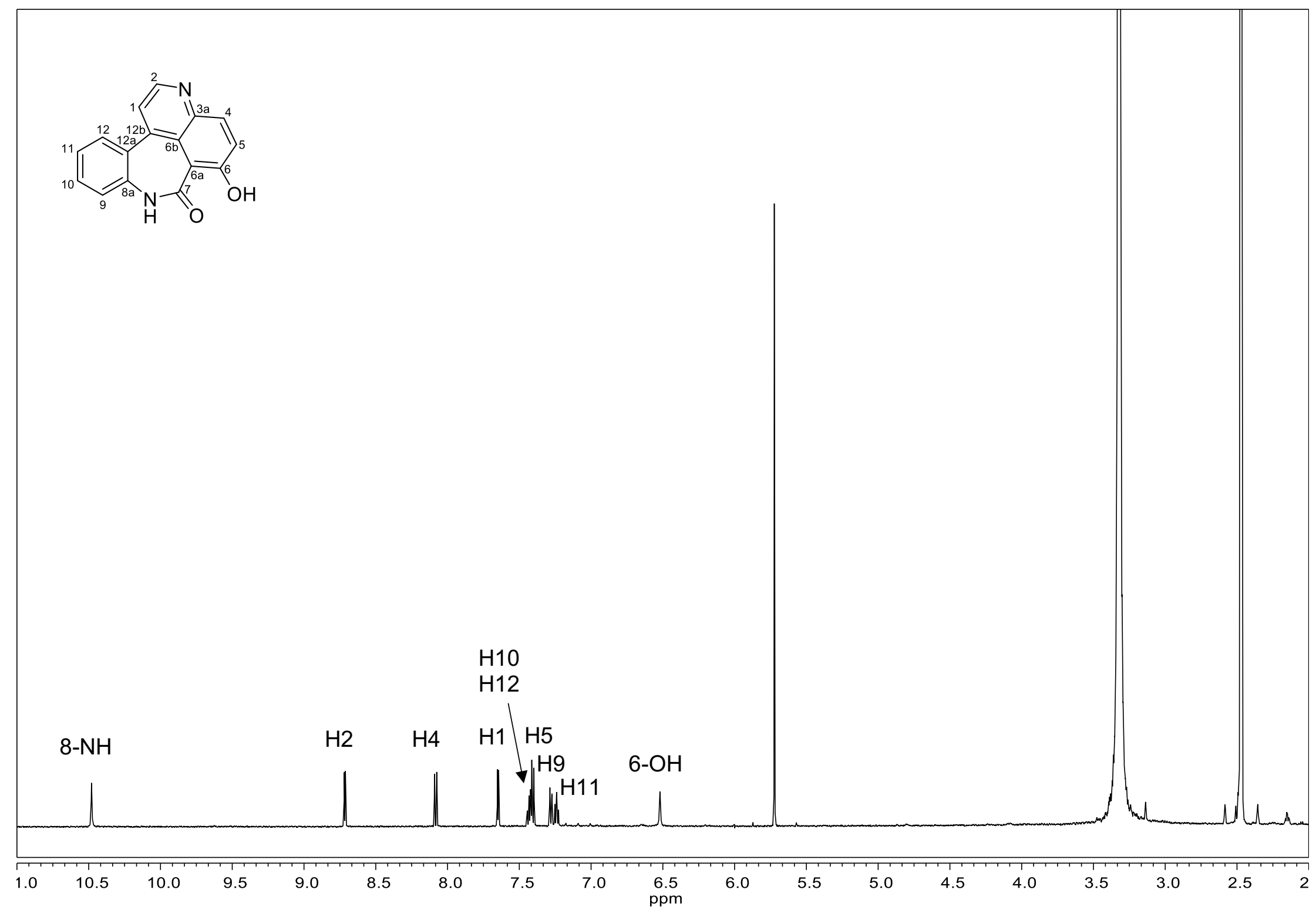

Figure S16. ${ }^{1} \mathrm{H}$ NMR spectrum of compound 1 in DMSO-d 


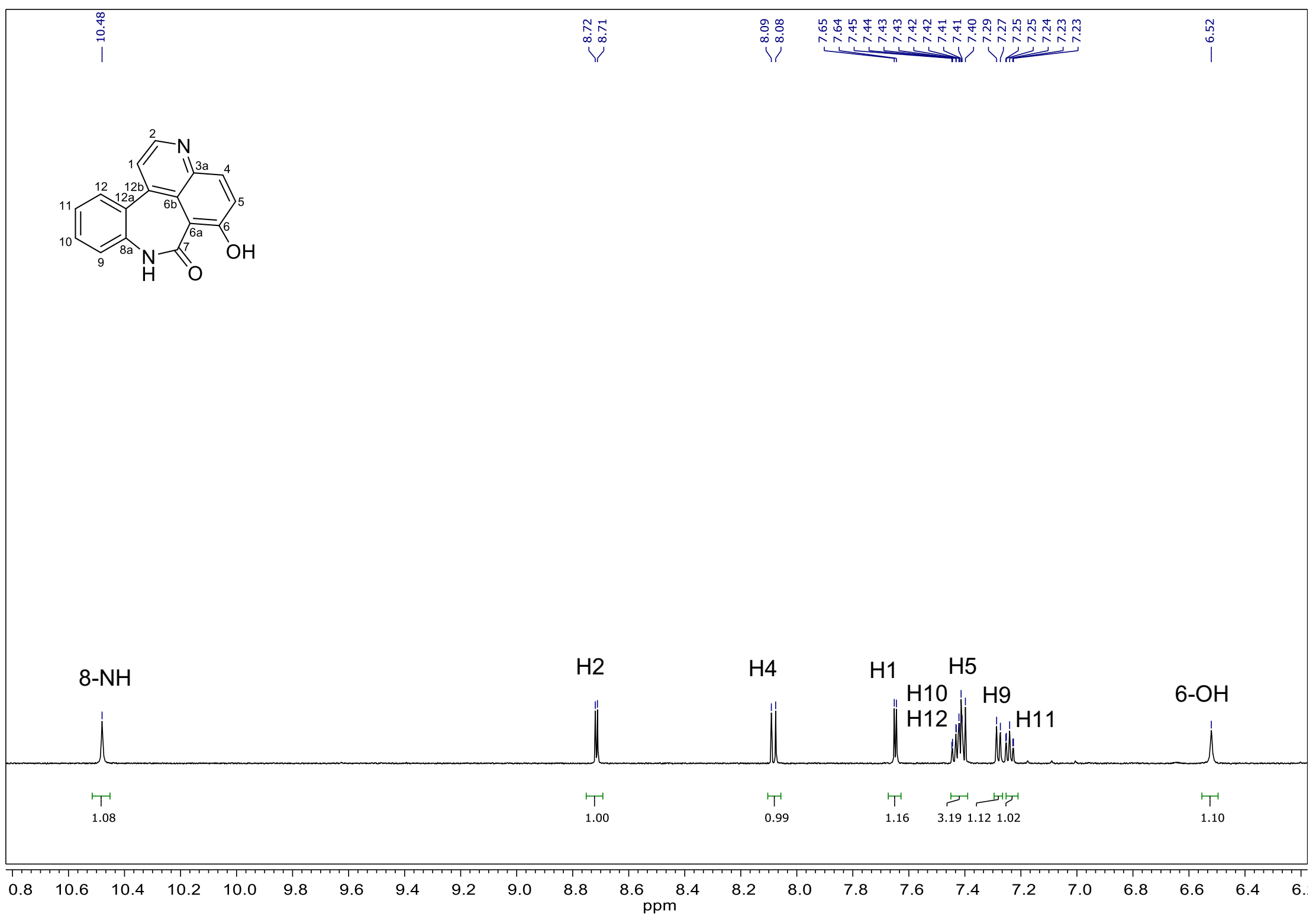

Figure S17. A blown-up spectrum of ${ }^{1} \mathrm{H}$ NMR of compound 1 in DMSO- $d_{6}$ 

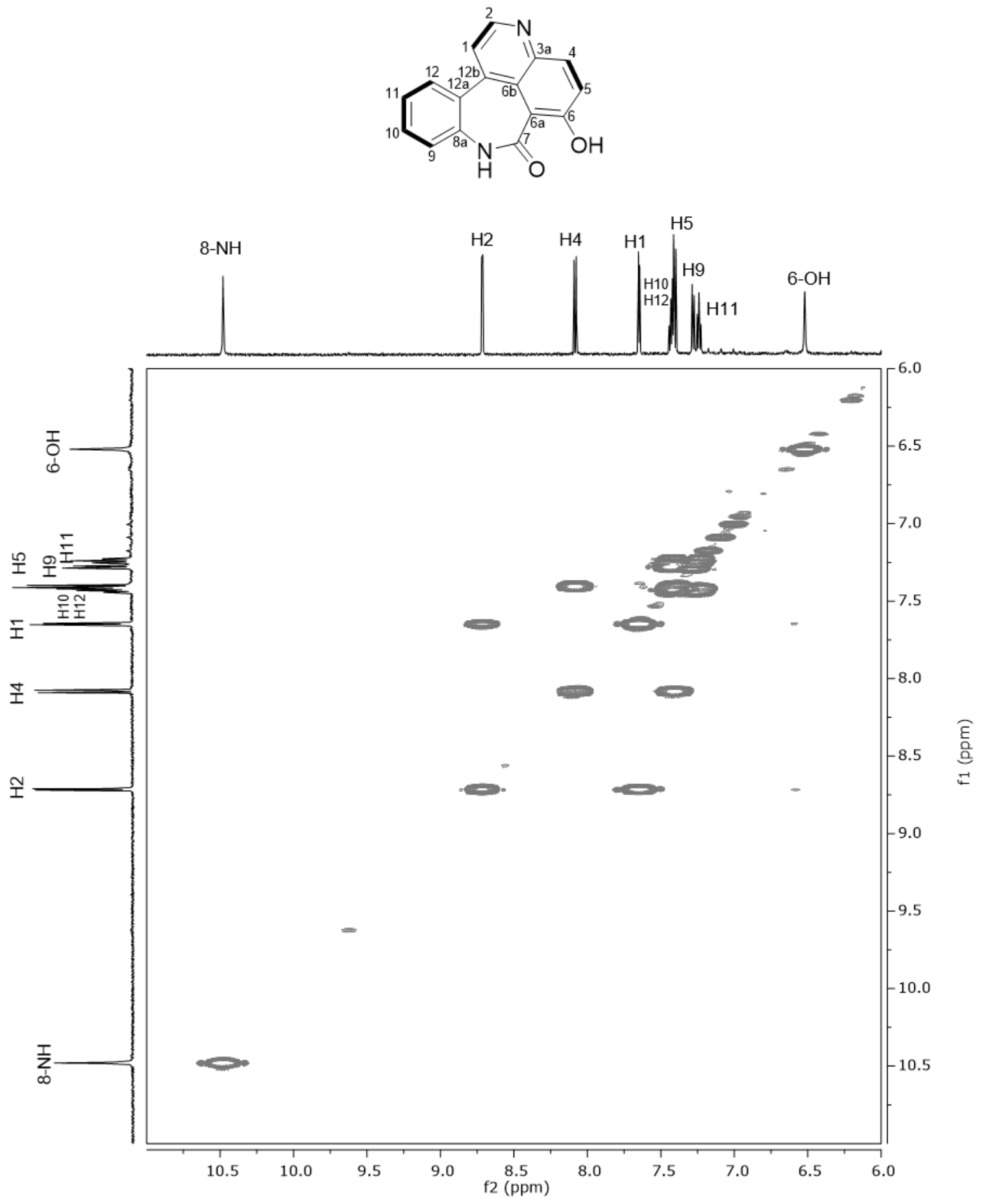

Figure S18. gCOSY NMR spectrum of compound 1 in DMSO-d 6 


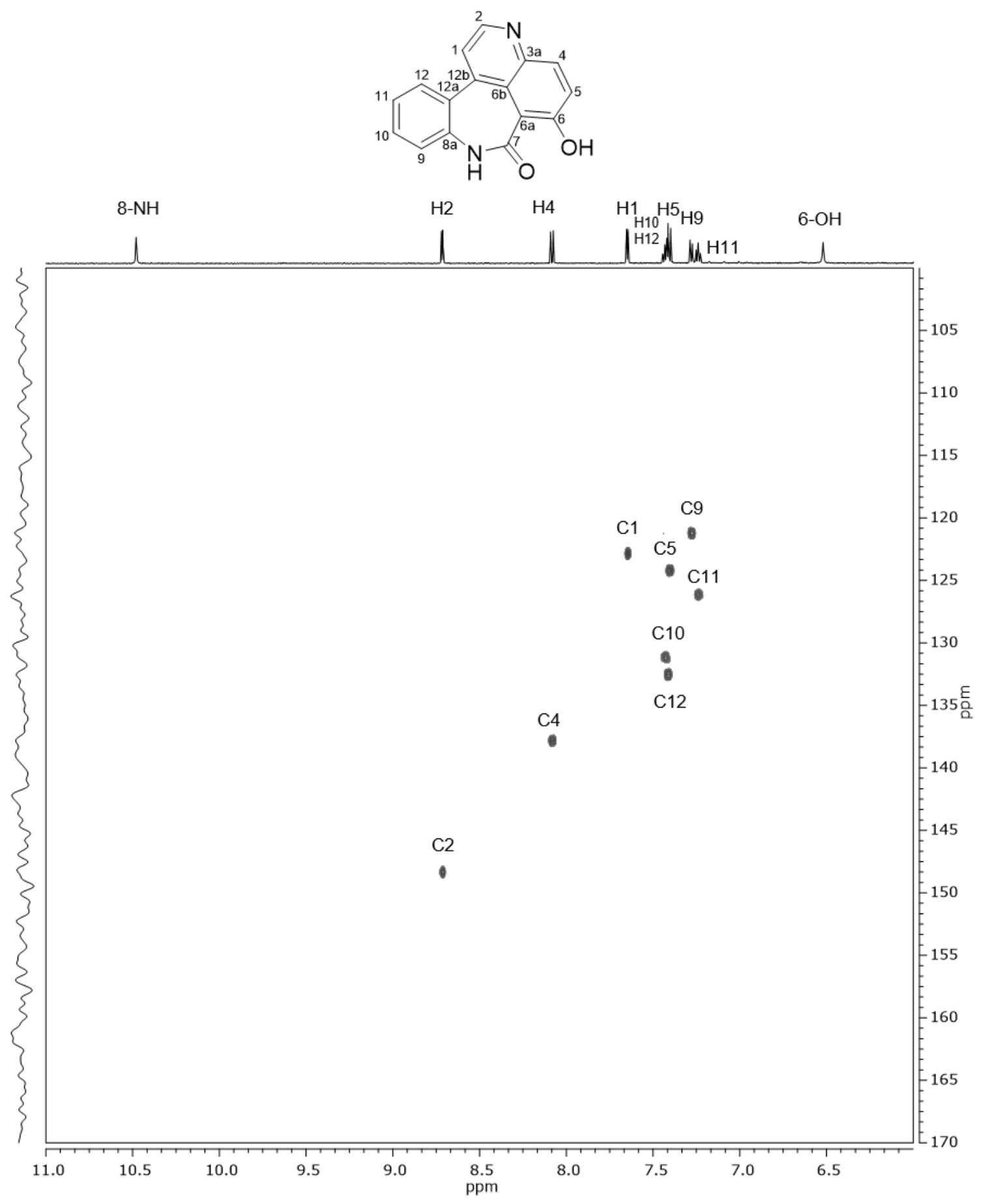

Figure S19. gHSQC NMR spectrum of compound 1 in DMSO-d 


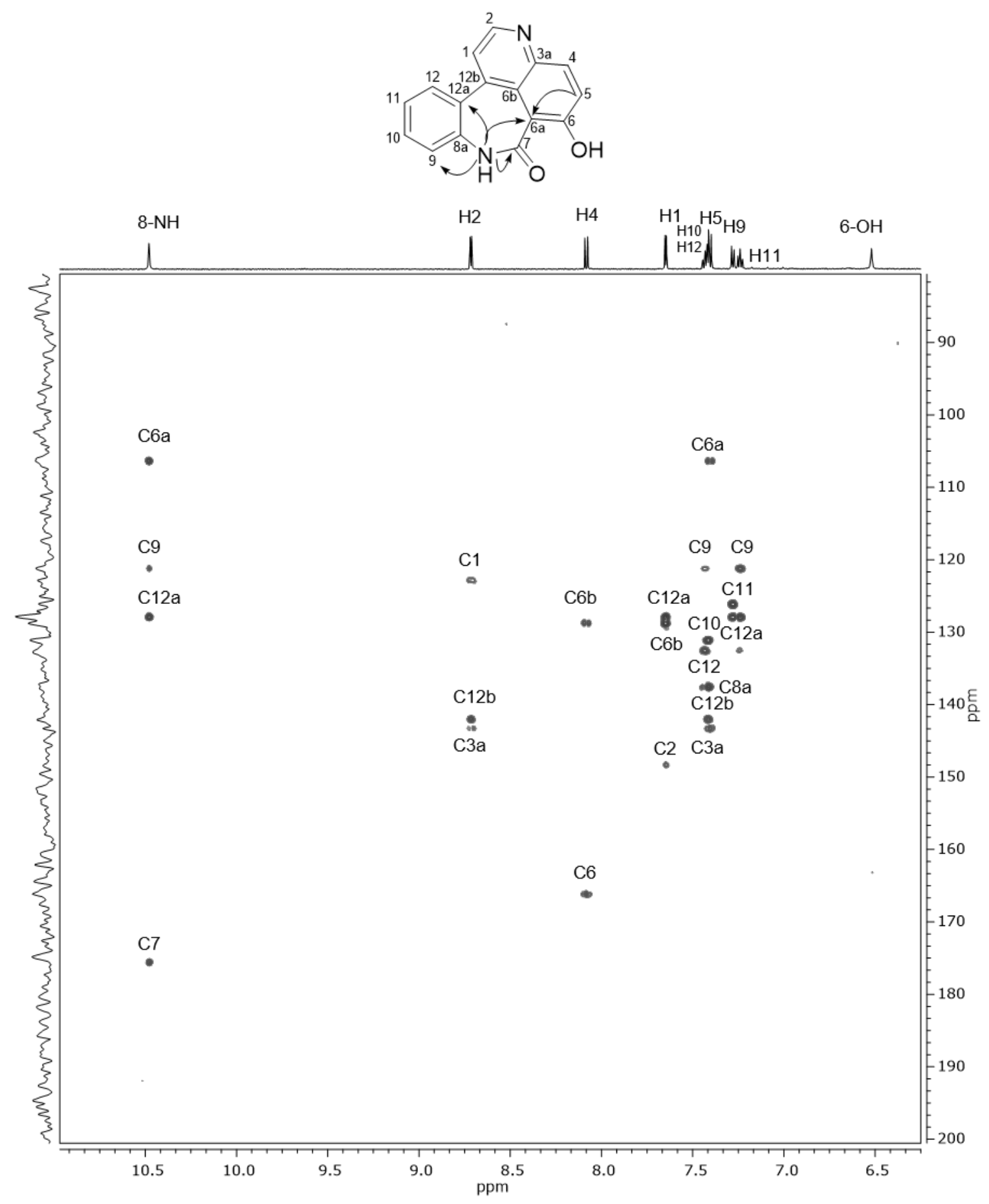

Figure S20. gHMBC NMR spectrum of compound 1 in DMSO- $d_{6}$ 


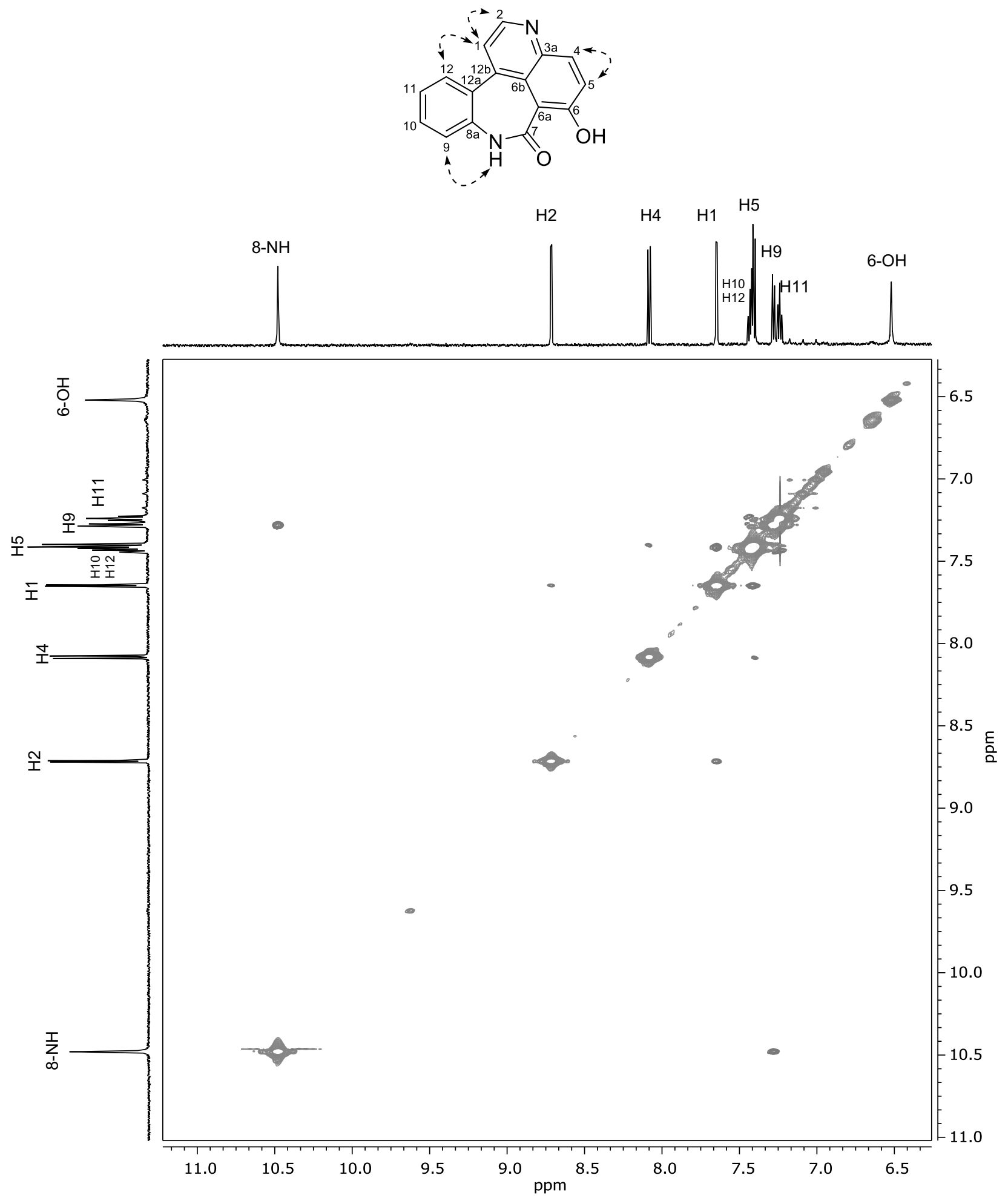

Figure S21. ROESY NMR spectrum of compound 1 in DMSO-d 6 


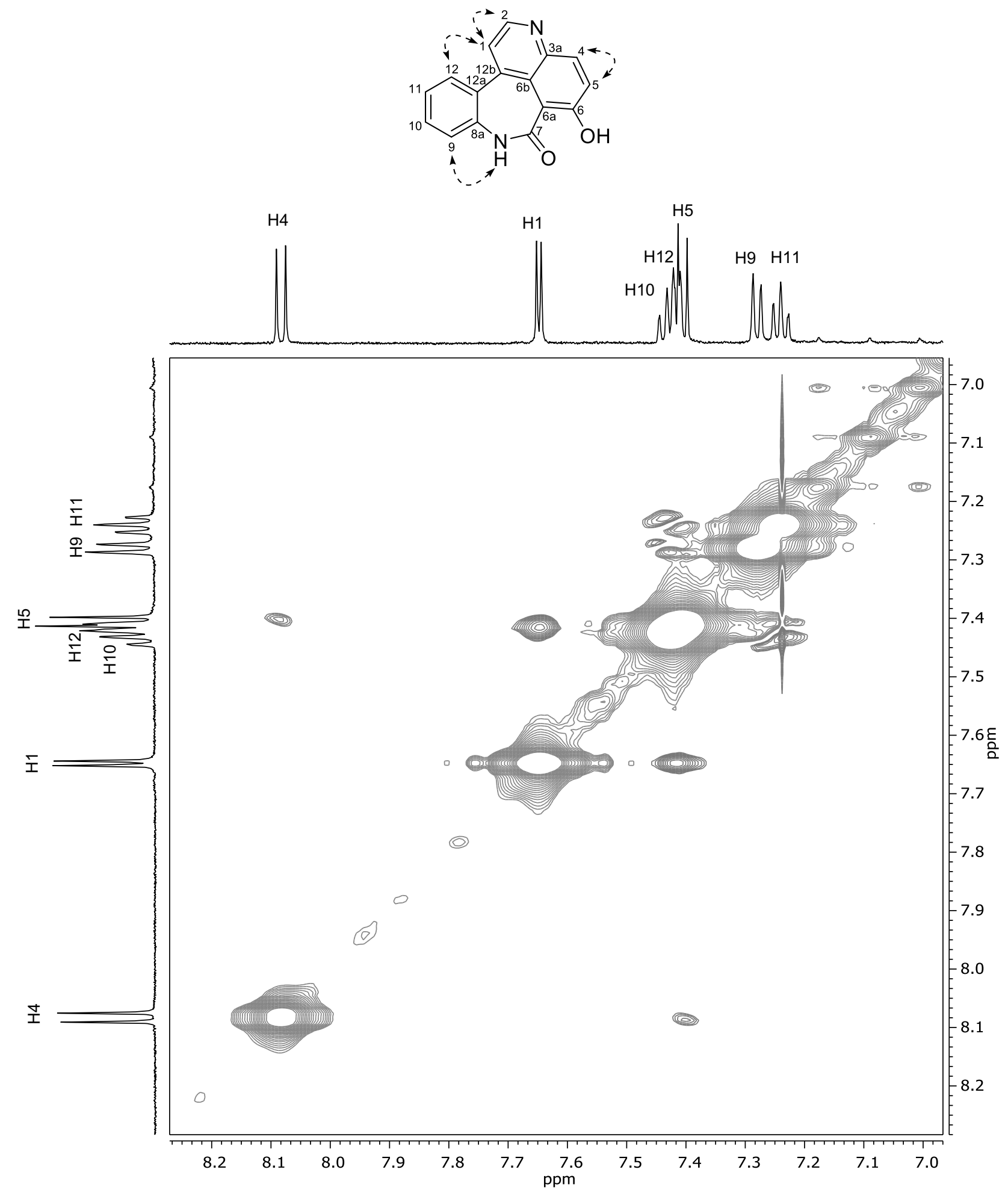

Figure S22. A blown-up spectrum of ROESY NMR of compound 1 in DMSO- $d_{6}$ 


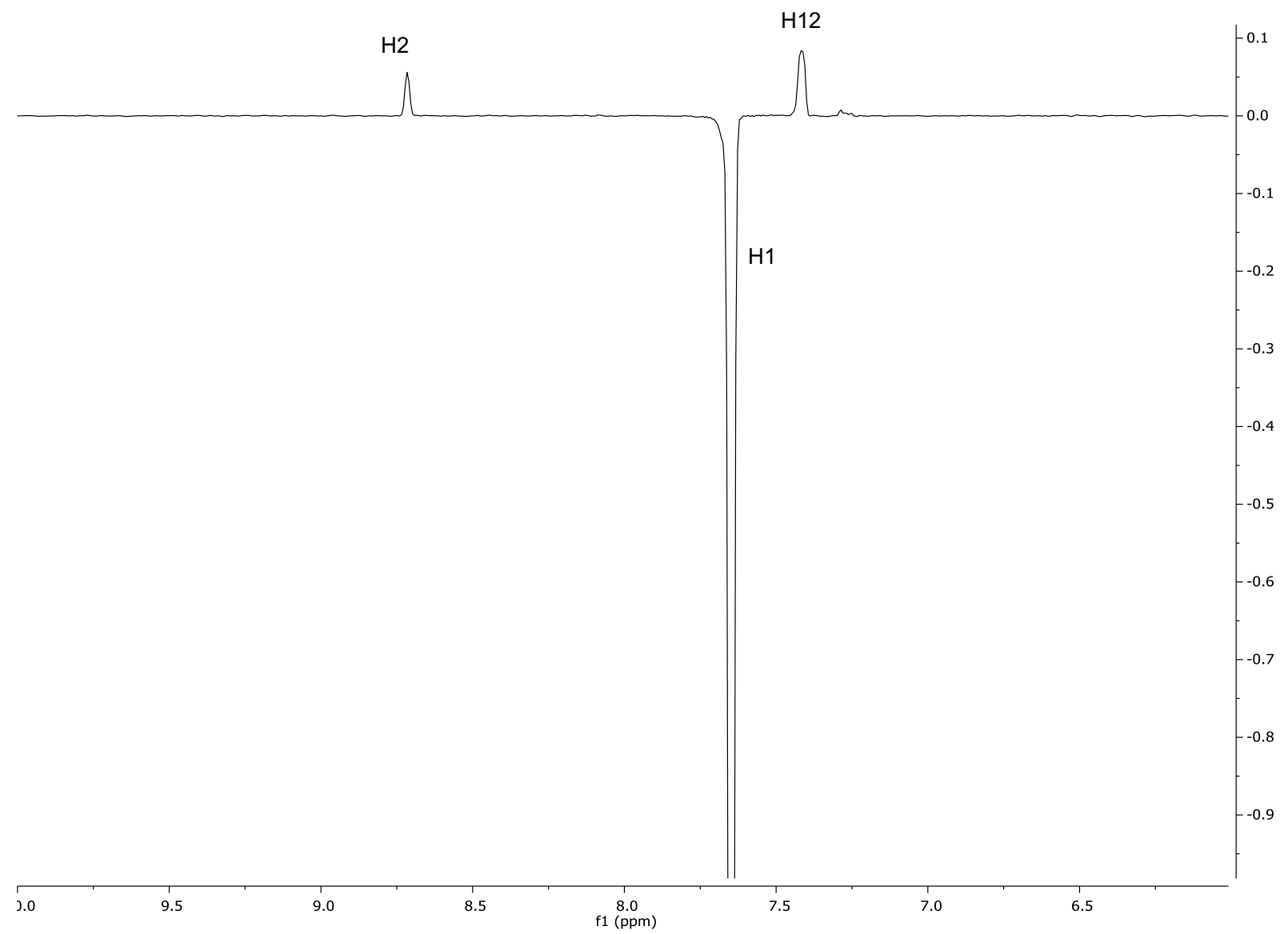

Figure S23. A 1D version of ROESY NMR spectrum of compound 1 in DMSO- $d_{6}$ 

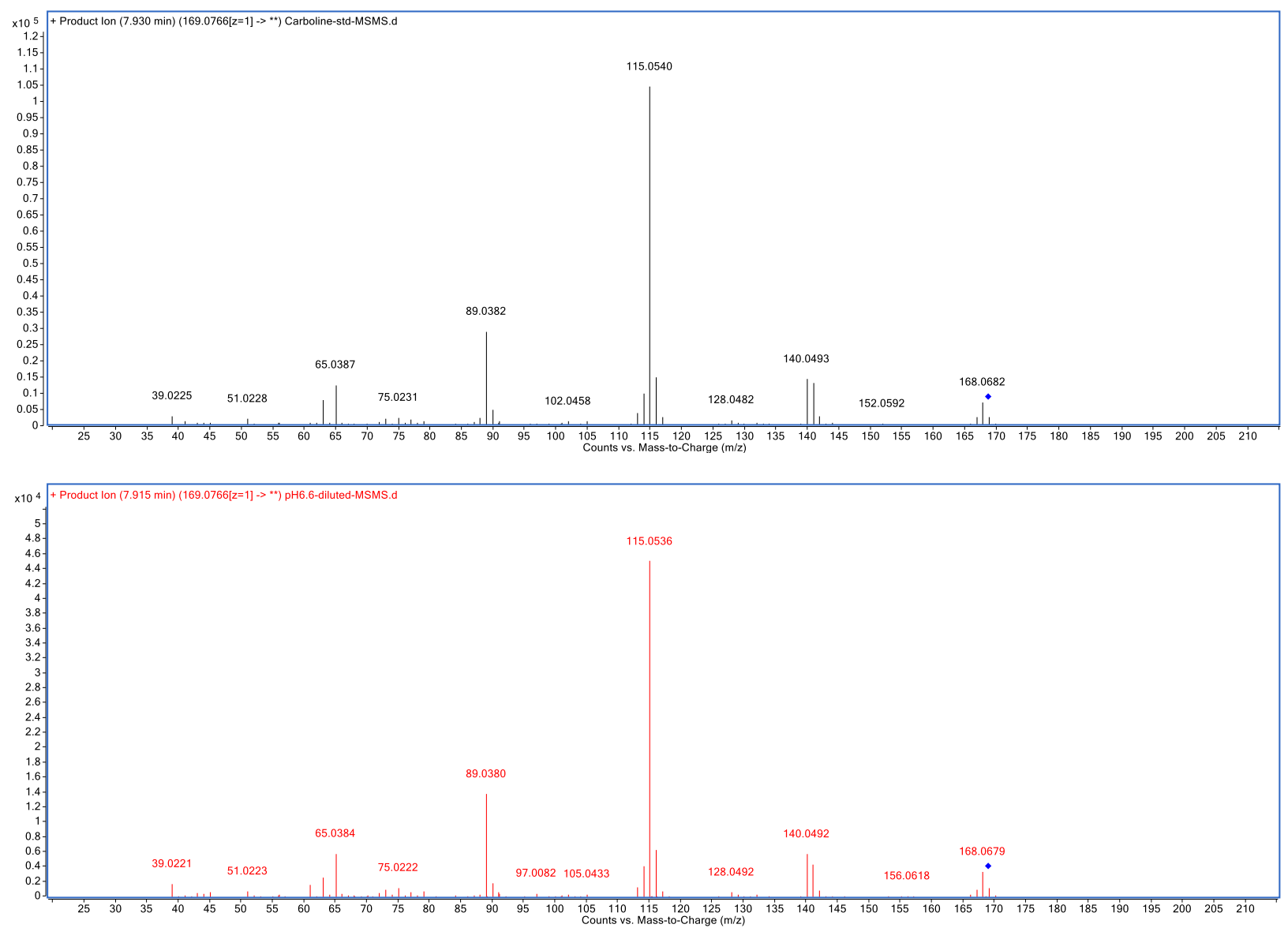

Figure S24. Tandem MS spectra of $\boldsymbol{\beta}$-carboline. (a) $\beta$-carboline commercial standard (b) $\beta$-carboline from Maillard reaction. 


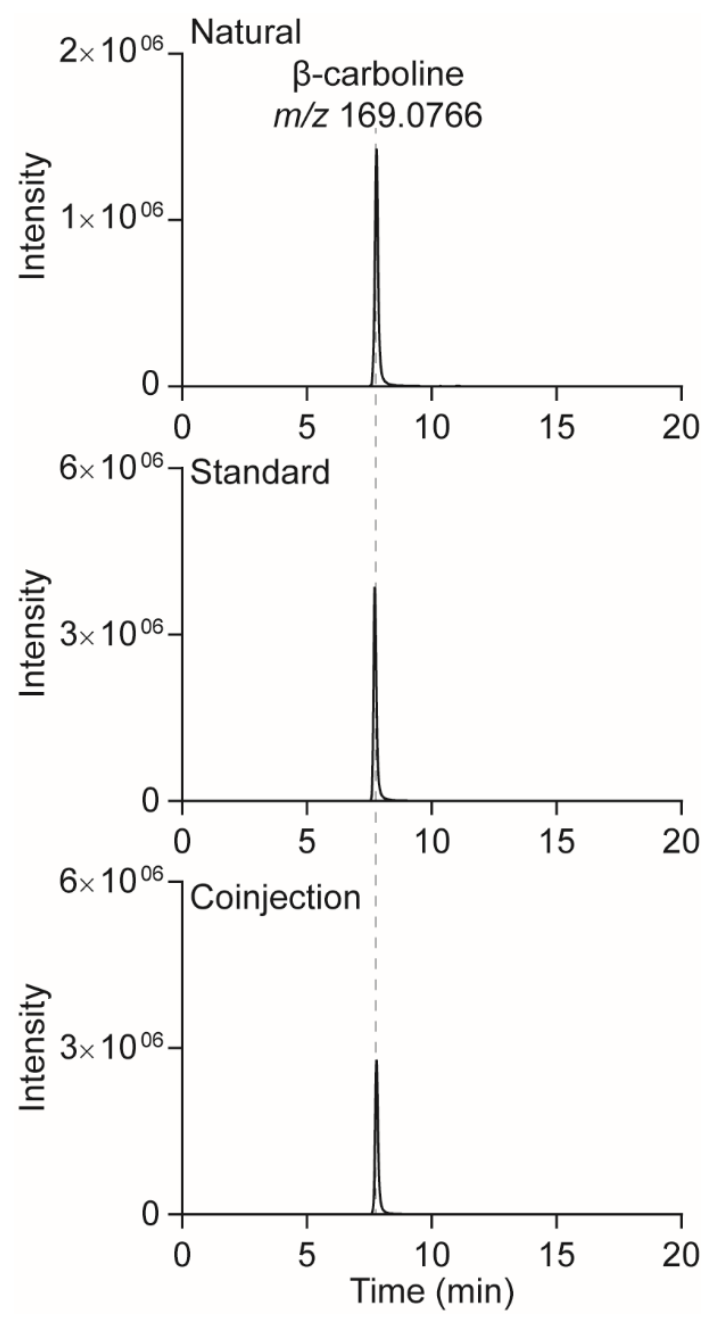

Figure S25. Identification of $\beta$-carboline from coinjection with commercial standard. 
Table S1. PCR Primers for E14504F

\begin{tabular}{|c|c|c|}
\hline Locus & Forward Primer & Reverse Primer \\
\hline ITS & $\begin{array}{l}\text { ITS3- } \\
\text { GCATCGATGAAGAACGCAGC }\end{array}$ & $\begin{array}{l}\text { ITS2- } \\
\text { GCTGCGTTCTTCATCGATGC }\end{array}$ \\
\hline LSU & $\begin{array}{l}\text { 5.8SR- } \\
\text { TCGATGAAGAACGCAGCG }\end{array}$ & $\begin{array}{l}\text { LR7- } \\
\text { TACTACCACCAAGATCT }\end{array}$ \\
\hline RPB2 & $\begin{array}{l}\text { fRPB2-5F- } \\
\text { GAYGAYMGWGATCAYTTYGG }\end{array}$ & $\begin{array}{l}\text { fRPB2-7cR- } \\
\text { CCCATRGCTTGYTTRCCCAT }\end{array}$ \\
\hline
\end{tabular}


Table S2.

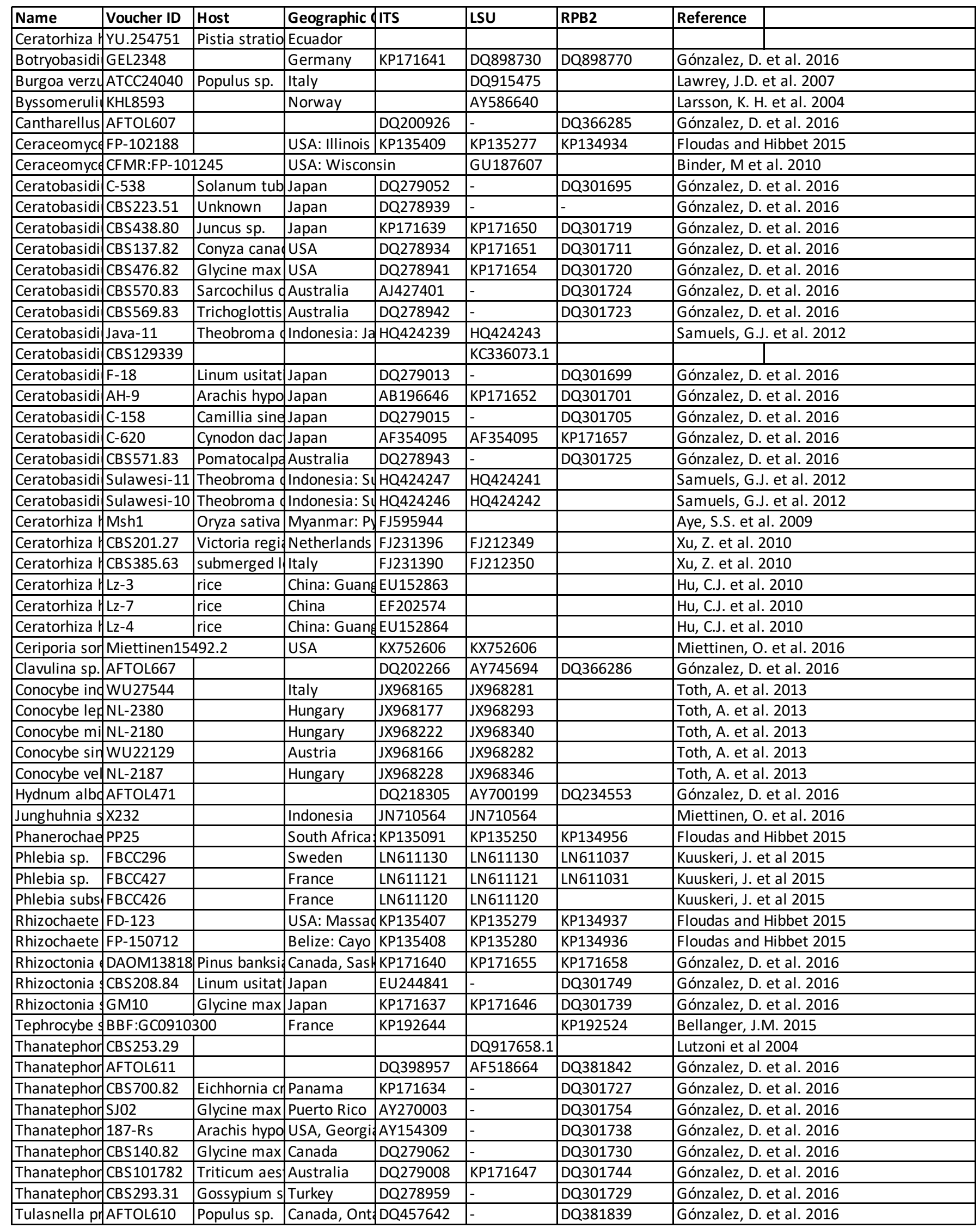

